\title{
Is the use of high correlated color temperature light at night related to delay of sleep timing in university students? A cross-country study in Japan and China
}

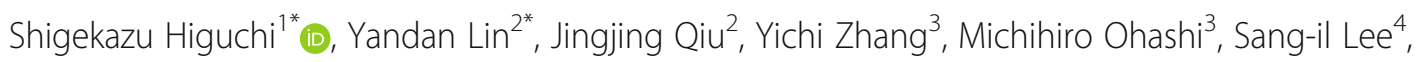
Shingo Kitamura ${ }^{5}$ and Akira Yasukouchi ${ }^{1}$

\begin{abstract}
Background: Blue-enriched white light at night has the potential to delay the circadian rhythm in daily life. This study was conducted to determine whether the use of high correlated color temperature (CCT) light at home at night is associated with delay of sleep timing in university students.

Methods: The survey was conducted in 2014-2015 in 447 university students in Japan and 327 students in China. Habitual sleep timing and type of CCT light at home were investigated by using a self-administered questionnaire. The Japanese students were significantly later than the Chinese students in bedtime, wake time, and midpoint of sleep. They were asked whether the lighting in the room where they spend most of their time at night was closer to warm color (low CCT) or daylight color (high CCT). The amount of light exposure level during daily life was measured for at least 1 week by the use of a light sensor in 60 students in each country.

Results: The percentages of participants who used high CCT lighting at night were $61.6 \%$ for Japanese students and $80.8 \%$ for Chinese students. Bedtime and sleep onset time on school days and free days were significantly later in the high CCT group than in the low CCT group in Japan. The midpoint of sleep in the high CCT group was significantly later than that in the low CCT group on free days but not on school days. On the other hand, none of the sleep measurements on school days and free days were significantly different between the high CCT and low CCT groups in China. Illuminance level of light exposure during the night was significantly higher in Japanese than in Chinese, but that in the morning was significantly higher in China than in Japan.
\end{abstract}

Conclusions: The use of high CCT light at night is associated with delay of sleep timing in Japanese university students but not in Chinese university students. The effects of light at night on sleep timing and circadian rhythm may be complicated by other lifestyle factors depending on the country.

Keywords: Circadian rhythm, Sleep, Blue light, Social jetlag, University students, International comparison

\footnotetext{
*Correspondence: higu-s@design.kyushu-u.ac.jp; ydlin@fudan.edu.cn

'Department of Human Science, Faculty of Design, Kyushu University, 4-9-1

Shiobaru, Minamiku, Fukuoka 815-8540, Japan

${ }^{2}$ Institute for Electric Light Sources, Fudan University, Shanghai 200433, China

Full list of author information is available at the end of the article
}

(c) The Author(s). 2021 Open Access This article is licensed under a Creative Commons Attribution 4.0 International License, which permits use, sharing, adaptation, distribution and reproduction in any medium or format, as long as you give appropriate credit to the original author(s) and the source, provide a link to the Creative Commons licence, and indicate if changes were made. The images or other third party material in this article are included in the article's Creative Commons licence, unless indicated otherwise in a credit line to the material. If material is not included in the article's Creative Commons licence and your intended use is not permitted by statutory regulation or exceeds the permitted use, you will need to obtain permission directly from the copyright holder. To view a copy of this licence, visit http://creativecommons.org/licenses/by/4.0/. The Creative Commons Public Domain Dedication waiver (http://creativecommons.org/publicdomain/zero/1.0/) applies to the data made available in this article, unless otherwise stated in a credit line to the data. 


\section{Background}

Light is a strong synchronizing agent (zeitgeber) for the circadian system. Light exposure in the morning has an important role in resetting the circadian rhythm to a 24$h$ cycle in humans. On the other hand, evening light exposure delays the phase of circadian rhythms. This relationship between the timing of light exposure and phase shift of circadian rhythms is known as a phase-response curve $[1,2]$. In addition to the effect on the circadian rhythm, light at night has an impact on suppression of melatonin secretion [3] and an increase in arousal level [4]. These physiological and endocrinological effects are known as non-visual effects of light and/or non-imageforming effects of light [5-7]. In modern society, most people spend the night safely and comfortably thanks to artificial lighting at night. However, excessive exposure to light at night has negative effects on human sleep and circadian rhythm [8].

The non-visual effects of light depend on the intensity of light, the spectrum of light, and the duration of exposure. The light intensity of even general home lighting is known to affect circadian rhythms and melatonin secretion $[9,10]$. Regarding the light spectrum, blue light is known to have a strong effect on melatonin suppression and phase shift of the circadian rhythm [11-13]. Intrinsically photosensitive retinal ganglion cells (ipRGCs), which contain a photopigment called melanopsin, have an important role in the action of blue light [14, 15]. The action of blue light is observed in blue-enriched polychromatic light, which is called high correlated color temperature (CCT) light. High CCT light has greater effects than low CCT light on arousal level and melatonin suppression [16-18]. The physiological effects of high CCT of a fluorescent lamp were reported even before the discovery of ipRGCs [19-22]. In recent years, similar results have been obtained by exposure to LED lighting [23-25].

However, many of those studies were conducted in a laboratory, and there have been few studies in which the influence of CCT of home lighting in real life was examined. We previously reported that there were significant correlations between CCT of lighting at home and phase of the circadian rhythm in middle-aged adults and primary school children in Japan [26]. The results of that study suggested that high CCT light at home might be a cause of the delay of the circadian phase in daily life. However, that study had a small sample size and there has been no study conducted in a large population. This study was conducted in a large number of university students. It is known that university students have the most night-typed sleep pattern [27].

Furthermore, the survey was conducted in Japan and China. Our previous study conducted in Japan showed that the CCT of lighting used in the home correlates with circadian rhythms [26]. However, sleep habits and circadian rhythms are influenced not only by the light environment but also by the lifestyle and social environment [28]. It is possible that the CCT of artificial lighting at night has an effect on sleep only in Japan. To generalize the effect of CCT on sleep in real life, it was necessary to research outside Japan. Therefore, this study also included Chinese university students living in a social environment different from that in Japan. We chose a location where the latitude of the study site, Shanghai in China, is almost the same as that of Fukuoka in Japan, and the times of sunrise and sunset are also almost the same.

The purpose of this study was to determine the differences between light environments in China and Japan and to clarify the relationship between light environments at night and sleep habits in university students in Japan and China.

\section{Methods \\ Participants}

The study was conducted in mid-December 2014 and mid-January 2015. The year-end and New Year holidays were excluded from the survey period. The participants included 470 Japanese university students and 397 Chinese university students. All participants provided informed written consent. The study was approved by the Institutional Ethics Committee of Kyushu University; the protocol and all the procedures were in agreement with the Declaration of Helsinki. After excluding participants whose data included typographical errors or for whom data were missing, we finally analyzed data for 447 Japanese students (average age of $21.5 \pm 1.6$ years) and 327 Chinese students (average age of $23.3 \pm 2.7$ years). The ratio of males in the Japanese students (62.8\%) was significantly higher than that in the Chinese students (53.4\%).

The survey was conducted in Fukuoka City in Japan and Shanghai City in China. The latitudes of Fukuoka and Shanghai are $33^{\circ} 36^{\prime}$ north latitude and $31^{\circ} 11^{\prime}$ north latitude, respectively. The time difference between Japan and China is $1 \mathrm{~h}$. The local times at sunrise on December 1st in Fukuoka and Shanghai were 7:04 and 6: 34 , respectively, and the local times at sunset were 17:10 and $16: 51$, respectively.

\section{Measurements of sleep habits}

We investigated the habitual bedtime (lights off time), subjective sleep latency, and wake time on school days and free days using a self-administered questionnaire. The sleep onset time was calculated by adding the sleep latency to the bedtime, and the sleep period time was calculated by the time from the sleep onset time to the wake time. The sleep midpoint was calculated by adding 
$1 / 2$ of the sleep period time to the sleep onset time. Social jet lag was calculated as the absolute difference between midpoint of sleep on free days and midpoint on school days [29].

Table 1 shows the sleep habits of the university students in Japan and China in the present study. After adjustments by sex and age, on both school days and free days, the Japanese students were significantly later than the Chinese students in all measurements including bedtime, sleep onset time, wake time, and midpoint of sleep $(p<0.001)$. Sleep period time was also significantly shorter in Japanese students than in Chinese students $(p<0.001)$. Subjective sleep latency was not significantly different between the two groups. Social jet lag was significantly larger in Japanese students than in Chinese students $(p<0.001)$.

\section{Measurements of light environments}

To the best of our knowledge, this study is the first study in which the type of CCT light used at home was investigated for a large sample using a questionnaire. Therefore, we originally made a simple two-choice question. The participants were asked whether the lighting in the room where they spend most of their time at night was closer to warm color (low CCT) or daylight color (high CCT). Color photographs were used to help participants make accurate selections. The participants looked at two photographs of lighting in the

Table 1 Demographic data and sleep habits in university students in Japan and China

\begin{tabular}{|c|c|c|c|}
\hline & $\begin{array}{l}\text { Japanese } \\
(n=447)\end{array}$ & $\begin{array}{l}\text { Chinese } \\
(n=327)\end{array}$ & \\
\hline Mean age (years) & $21.5(1.6)$ & $23.3(2.7)$ & $* *$ \\
\hline Sex, \%male & 62.8 & 53.4 & ** \\
\hline \multicolumn{4}{|l|}{ Sleep habits (school days) } \\
\hline Bedtime & $01: 09(1: 01)$ & $23: 58(0: 43)$ & $* * *$ \\
\hline Sleep latency (min) & $15.1(11.3)$ & $16.1(11.7)$ & n.s. \\
\hline Sleep onset time & $01: 24(1: 02)$ & $00: 15(0: 46)$ & *** \\
\hline Wake time & 08:01 (1:11) & $07: 42(0: 49)$ & $* * *$ \\
\hline Midpoint of sleep & $04: 43(0: 57)$ & $3: 58(0: 39)$ & $* * *$ \\
\hline Sleep period time (h) & $6.62(1.13)$ & $7.46(0.90)$ & $* * *$ \\
\hline \multicolumn{4}{|l|}{ Sleep habits (free days) } \\
\hline Bedtime & $01: 37(1: 12)$ & $00: 22(0: 51)$ & *** \\
\hline Sleep latency (min) & $16.0(13.0)$ & $14.9(11.7)$ & n.s. \\
\hline Sleep onset time & $01: 52(1: 14)$ & $00: 38(0: 52)$ & $* * *$ \\
\hline Wake time & $09: 35(1: 25)$ & $08: 46(1: 01)$ & $* * *$ \\
\hline Midpoint of sleep & $05: 45(1: 11)$ & $4: 42(0: 49)$ & $* * *$ \\
\hline Sleep period time (h) & $7.70(1.25)$ & $8.15(0.95)$ & $* * *$ \\
\hline Social jet lag (h) & $1.04(0.82)$ & $0.73(0.56)$ & $* * *$ \\
\hline
\end{tabular}

Values are means and SD

Adjusted by age and sex ${ }^{* *} p<0.01,{ }^{* *} p<0.001$, n.s not significant questionnaire and chose one of them. The photographs used in the questionnaire in this study are not allowed to be shown here due to copyright issues, but almost the same pictures are shown as a supplemental file (see Additional file 1).

In addition, we asked 60 Japanese and 60 Chinese subjects to wear a pendant-type illuminance sensor (HOBO by Onset UA-002-08) and illuminance was continuously measured for about 2 weeks at 2-min intervals. After exclusion of subjects due to missing data, data for 54 Japanese students $(22.5 \pm 2.2$ years old, \%male $=51.9)$ and 58 Chinese students $(22.6 \pm 2.2$ years old, \%male $=50.4)$ were used for analysis. Sleep timing was significantly later in Japanese students than in Chinese students (Additional file 2).

The resolution of illuminance was about $10 \mathrm{~lx}$. The subjects were instructed to always wear the sensor while awake, except for exercise and bathing, and keep it at the bedside while sleeping. First, the average illuminance was calculated for each hour to see the change over a period of $24 \mathrm{~h}$. In another way, illuminance level was calculated on the basis of habitual bedtime. Average illuminance level for $2 \mathrm{~h}$ before habitual bedtime was used as a representative illuminance level before bedtime at home at night for each participant. Data with $0 \mathrm{~lx}$ before habitual bedtime were excluded from the calculations. Due to the limited number of measurement days on free days, the data for free days and school days were not separated.

\section{Statistical analysis}

The chi-square test was used for comparison of the percentages of Japanese and Chinese students who use high CCT lighting. As for the illuminance level, a t-test was conducted after logarithm transformation. A comparison of sleep measurements between CCT lighting conditions was made by adjusting age and sex using a linear mixed model since sleep timing and sleep hours are affected by sex and age [27]. Pearson's correlation analysis was performed for illuminance level and sleep measurements.

\section{Results}

The percentages of participants who used high CCT lighting at night were $61.6 \%$ for Japanese students and $80.8 \%$ for Chinese students (Fig. 1). The percentage of participants who used high CCT lighting was significantly higher for Chinese students (chi-square test, $p<$ 0.05). Sleep habits were compared in the high CCT group and the low CCT group for both Japanese students and Chinese students after adjusting for sex and age. In the Japanese students, bedtime and sleep onset time in the high CCT group were significantly later than those in the low CCT group on school days $(p<0.05)$ and free days $(p<0.01)$ (Table 2). Also, the midpoint of 


\section{口Low CCT aHigh CCT}

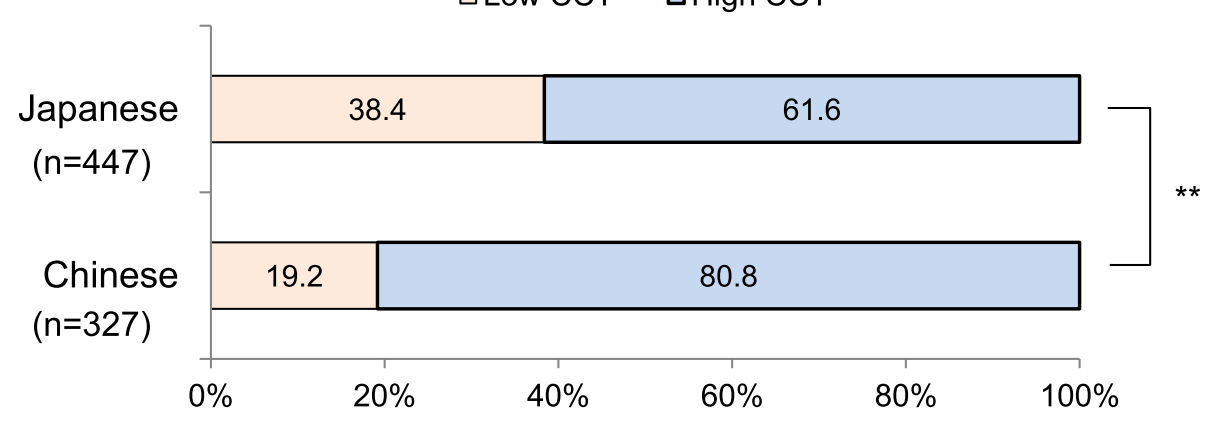

Fig. 1 Percentages of users of high CCT light and low CCT light at home at night in Japanese and Chinese university students. ${ }^{* *} p<0.01$

sleep in the high CCT group was significantly later than that in the low CCT group on free days $(p<0.01)$ (Fig. 2). The wake time on flee days tended to be later $(p=0.052)$ and social jet lag $(p=0.051)$ tended to be larger in the high CCT group than in the low CCT group. On the other hand, in the Chinese students, there was no significant difference in sleep measurements between the high CCT group and the low CCT group on school days or free days (Table 3 ).

Figure 3 shows the changes in illuminance level that the participants were exposed to for $24 \mathrm{~h}$. The average illuminance in the evening (18:00-24:00) was significantly higher for the Japanese students than for the Chinese students $(t=5.938, p<0.001)$. The average illuminance was significantly higher for the Japanese students than for the Chinese students during the period

Table 2 Sleep habits on school days and free days in university students in Japan

\begin{tabular}{llll}
\hline Japanese & $\begin{array}{l}\text { High CCT } \\
(\boldsymbol{n}=\mathbf{2 7 5})\end{array}$ & $\begin{array}{l}\text { Low CCT } \\
(\boldsymbol{n}=\mathbf{1 7 2})\end{array}$ & $\boldsymbol{P}$ value \\
\hline Sleep habits (school days) & & & \\
$\quad$ Bedtime & $01: 13(0: 58)$ & $01: 00(1: 04)$ & $0.029 *$ \\
Sleep latency (min) & $15.5(11.8)$ & $15.1(10.7)$ & 0.668 \\
Sleep onset time & $01: 29(1: 00)$ & $01: 15(1: 05)$ & $0.026^{*}$ \\
Wake time & $08: 02(1: 13)$ & $07: 59(1: 10)$ & 0.476 \\
Midpoint of sleep & $04: 45(0: 57)$ & $4: 37(0: 59)$ & 0.100 \\
Sleep period time (h) & $6.55(1.14)$ & $6.74(1.11)$ & 0.186 \\
Sleep habits (free days) & & & \\
$\quad$ Bedtime & $01: 45(1: 13)$ & $01: 25(1: 11)$ & $0.003 * *$ \\
Sleep latency (min) & $16.1(13.3)$ & $16.1(12.6)$ & 0.949 \\
Sleep onset time & $02: 02(1: 16)$ & $01: 41(1: 11)$ & $0.003 * *$ \\
Wake time & $09: 41(1: 27)$ & $09: 26(1: 20)$ & 0.052 \\
Midpoint of sleep & $05: 51(1: 11)$ & $05: 33(1: 08)$ & $0.006 * *$ \\
Sleep period time (h) & $7.65(1.33)$ & $7.74(1.12)$ & 0.495 \\
Social jet lag (h) & $1.09(0.84)$ & $0.94(0.78)$ & 0.051 \\
\hline
\end{tabular}

Values are means and SD.

Adjusted by age and sex ${ }^{*} p<0.05,{ }^{* *} p<0.01$ from midnight to early morning (0:00-6:00) including sleeping time $(t=7.573, p<0.001)$. On the other hand, the average illuminance in the morning (6:00-12:00) was significantly higher for the Chinese students than for the Japanese students $(\mathrm{t}=-2.038, p<0.05)$. There was no significant difference between illuminance levels in the afternoon (12:00-18:00) for the Japanese students and Chinese students. The average illuminance level for $2 \mathrm{~h}$ before habitual bedtime was significantly higher for the Japanese students $(74.8 \mathrm{~lx} \pm 56.5 \mathrm{~lx})$ than for the Chinese students $(59.9 \mathrm{~lx} \pm 64.8 \mathrm{~lx})(\mathrm{t}=7.573, p<0.01)$. Correlation analysis was conducted for illuminance level for 2 $\mathrm{h}$ before habitual bedtime at night and sleep habits. There was no significant correlation between illuminance level and any of the sleep measurements for both the Japanese students and Chinese students.

\section{Discussion}

The results of investigation of the relation between the CCT of lighting and sleep habits in each country showed that bedtime and sleep onset time of the students who used high CCT lighting was significantly later on school days and free days for the Japanese students. Previous laboratory studies showed that high CCT lighting (blueenriched white lighting) has a greater impact on arousal level and melatonin suppression [16-18]. The present study supported the results of previous studies conducted in a laboratory, and the association between use of high CCT lighting at night and delay of sleep timing was confirmed in the real world in a large sample of Japanese students. The delay in sleep timing for users of high CCT lighting in Japan is thought to be caused by an increase in alertness and delay of the circadian rhythm induced by exposure to blue-enriched light before bedtime.

The difference between sleep habits of students in the high CCT group and the low CCT group in Japan was more pronounced on free days than on school days. The midpoint of sleep on free days was significantly later in the high CCT group than in the low CCT group (Fig. 2). 


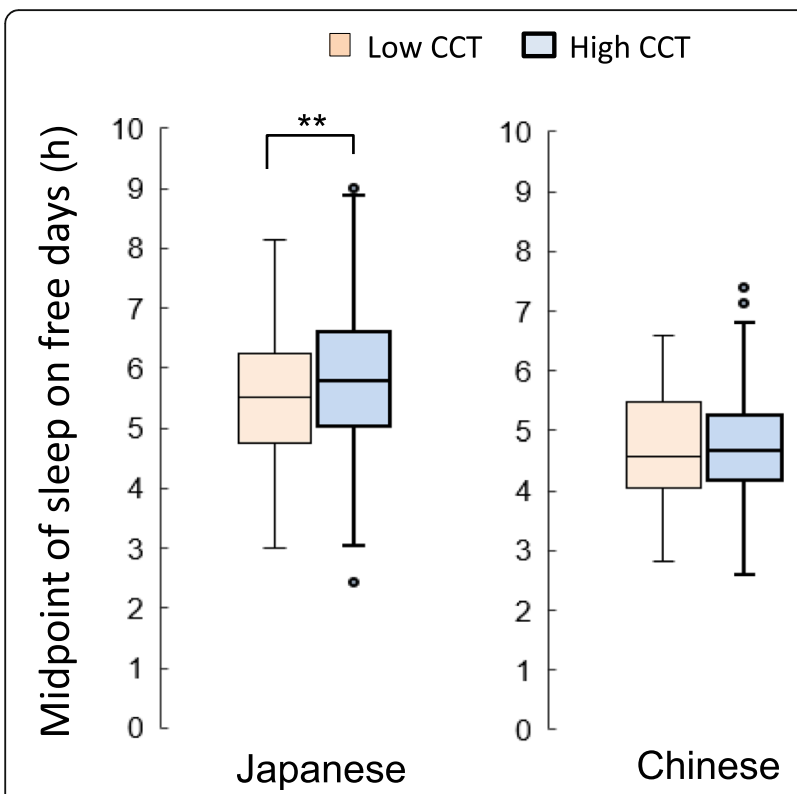

Fig. 2 Box plots of the midpoints of sleep on free days in the high CCT group and the low CCT group in Japanese (left) and Chinese (right). ${ }^{* *} p<0.01$

Also, wake-up time on free days tended to be delayed in the high CCT group. Therefore, the delay in the midpoint of sleep on free days might be caused not only by the delay in bedtime but also by the delay in wake-up time. It is known that a free day without social restriction tends to reflect individual chronotypes [30].

Table 3 Sleep habits on school days and free days in university students in China

\begin{tabular}{llll}
\hline Chinese & $\begin{array}{l}\text { High CCT } \\
(\boldsymbol{n = 2 7 1 )}\end{array}$ & $\begin{array}{l}\text { Low CCT } \\
(\boldsymbol{n}=\mathbf{5 6})\end{array}$ & $\boldsymbol{P}$ value \\
\hline Sleep habits (school days) & & & \\
Bed time Bedtime & $23: 58(0: 43)$ & $00: 01(0: 46)$ & 0.790 \\
Sleep latency (min) & $16.1(10.4)$ & $16.2(16.9)$ & 0.891 \\
Sleep onset time & $00: 14(0: 45)$ & $00: 17(0: 48)$ & 0.770 \\
Wake time & $07: 41(0: 48)$ & $07: 45(0: 55)$ & 0.442 \\
Midpoint of sleep & $03: 58(0: 38)$ & $04: 01(0: 43)$ & 0.510 \\
Sleep period time (h) & $7.45(0.88)$ & $7.48(0.92)$ & 0.645 \\
Sleep habits (free days) & & & \\
$\quad$ Bedtime & $00: 23(0: 50)$ & $00: 22(0: 58)$ & 0.803 \\
Sleep latency (min) & $14.7(10.3)$ & $15.7(16.9)$ & 0.561 \\
Sleep onset time & $00: 38(0: 51)$ & $00: 37(0: 57)$ & 0.909 \\
Wake time & $08: 48(1: 02)$ & $08: 42(0: 59)$ & 0.508 \\
Midpoint of sleep & $04: 43(0: 49)$ & $04: 40(0: 53)$ & 0.633 \\
Sleep period time (h) & $8.16(0.99)$ & $8.08(0.75)$ & 0.544 \\
Social jet lag (h) & $0.79(0.54)$ & $0.75(0.67)$ & 0.153 \\
\hline
\end{tabular}

Values are means and SD

Adjusted by age and sex
Furthermore, in this study, social jet lag tended to increase with high CCT. Social jet lag is known to be larger in night type persons [31,32]. From the above, this result suggests that the use of high CCT at night is associated with the night type chronotype. It has been reported that social jet lag is associated with obesity [29], depressive state [33], academic performance [34], and menstrual symptoms [35]. Further analysis of the associations between light environments, sleep, and health status is needed.

In the present study, significant differences in sleep habits between lighting conditions were found in Japanese students but not in Chinese students. One of the reasons for this difference may be the difference in illuminance level. Illuminance level after sunset for the Japanese students was significantly higher than that for the Chinese students. It is known that the effects of light also depend on the illuminance [4]. Therefore, it is possible that the effect of the CCT of light on sleep habits was small under the condition of the lower illuminance level in China. In contrast to light at night, the amount of light exposure in the morning was significantly larger in the Chinese students than in Japanese students. This suggests that the reset of the circadian rhythm by morning light exposure in China might prevent bedtime delay even though high CCT lighting is used at night.

Furthermore, the effects of light at night on sleep timing may be complicated by other lifestyle factors depending on the country. For example, in this study, about $80 \%$ of the Chinese students lived in dormitories and about $70 \%$ of the Japanese students lived alone. Chinese students lived with quite regular timetables for classes. Weak social pressure for a sleep/wake schedule is considered to be related to the delay of sleep pattern in Japanese students. This means that Japanese students are exposed to artificial lighting for a longer period of time before going to bed, which might be a cause of the delay of circadian rhythm as shown in a previous study [36]. In other words, relatively strong social pressure for sleep/wake timing in Chinese students might reduce the effects of light at night on sleep and circadian rhythm. When Japanese students were divided into those who lived alone and those who lived with their families, the effect of CCT was more pronounced among students who lived alone. This suggests that fewer social constraints for sleep habits make university students more susceptible to light at night. The relationship between the type of social constraints and the effect of night light on sleep needs to be examined in the future.

In this study, more than half of the Japanese and Chinese students used high CCT lighting at night. This result reflects the fact that it is common to use white and high CCT fluorescent lighting at night at home in some Asian countries including Japan and China. The percentage of 

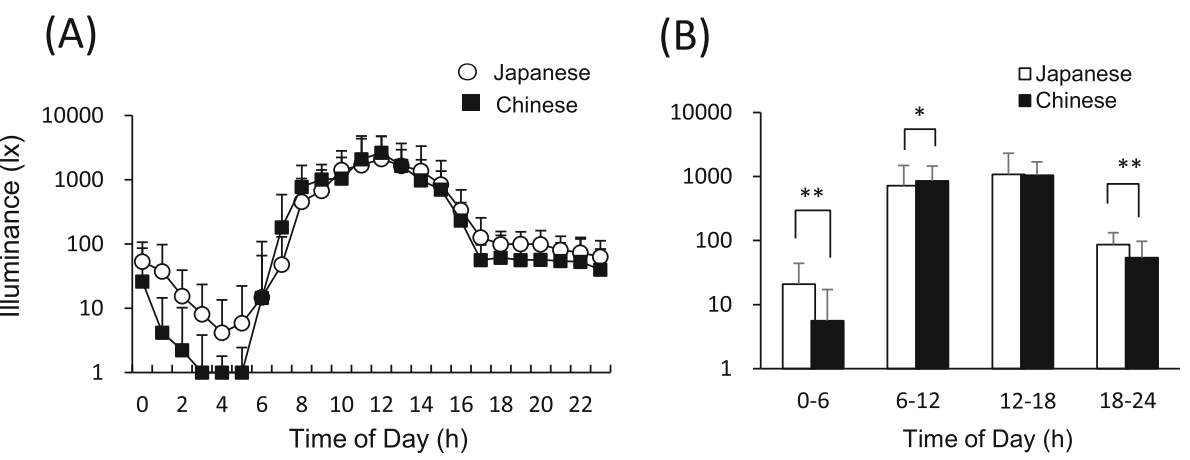

Fig. 3 Changes in the illuminance level that the participants were exposed to for $24 \mathrm{~h}$ in Japan $(n=54)$ and China $(n=58)(\mathbf{A})$. The illuminance on the vertical axis is displayed in logarithm. Average illuminance levels from midnight to early morning (0:00-6:00), in the morning (6:00-12:00), in the afternoon (12:00-18:00), and in the evening (18:00-24:00) (B). Data are shown as averages and standard deviations. $\left({ }^{*} p<0.05\right.$, $\left.{ }^{* *} p<0.01\right)$

students using high CCT lighting was significantly higher in Chinese students. The exact reason why white fluorescent lights are often used at home at night in Asia is not known. White fluorescent lighting began to become popular in Japan after the 1950s, and white fluorescent lighting becomes the preferred alternative to incandescent light in ordinary households. In the 1980s, fluorescent lamps with low CCT began to be sold, and it is thought that low CCT lighting has gradually become widespread in Japan. On the other hand, in China, low CCT fluorescent lights are not widely sold in stores and are not widely used at home. This may be one of the reasons for the differences between Japan and China. Currently, LED lighting is rapidly becoming widespread in both Japan and China. Since the CCT of LEDs can be easily adjusted, the lighting environment at home may be changing. Further research is needed because the lighting environment can be influenced by culture and technology.

For the survey of CCT light environments, we did not test its validity since it was a simple question. When the survey was conducted in 2014-2015, daylight color and warm color fluorescent lamps or incandescent lamps were generally used at home in Japan and China. Today, however, LED lighting with continuous color adjustment functions is widespread, and we may therefore need to be more careful about a survey of CCT of light using a questionnaire.

There were no significant correlations between illuminance level at night and sleep habits in this study. One reason may be that this study was a field study that included some uncontrolled factors affecting sleep habits other than the lighting condition at night. Although the purpose of this study was not to investigate the cause of differences in sleep habits of Chinese students and Japanese students, it is necessary to consider these factors that influence sleep habits. The low reliability of measurements of illuminance level using the pendant sensor is also a possible cause. For example, the problems with pendant-type sensors are that they may be hidden by clothing and the orientation of the sensor is not stable. Reliable measurements of illuminance level are needed to evaluate the relationships between individual sleep habits and illuminance levels at home. In addition, only 60 of the 447 Japanese and 60 of the 327 Chinese participants had their illuminance measured. Unfortunately, due to the small sample size in this study, we were also unable to examine the interaction between CCT and illuminance level.

Furthermore, the relationship between illuminance level and sleep habits may be complicated by individual differences in circadian photosensitivity [37-40]. In our previous studies, we found that polymorphisms in the melanopsin gene $(O P N 4)$ are associated with both the non-visual effects of light and the timing of sleep in Japanese university students $[40,41]$. It would be interesting to compare the association between gene polymorphisms and sleep habits in both countries in the future.

In conclusion, the use of blue-enriched white light (high CCT light) at night is associated with delay of sleep timing in Japanese university students but not in Chinese university students. Although the effects of light at night on sleep timing and circadian rhythm may be complicated by other lifestyle factors depending on the country, use of low CCT light at home at night is recommended to prevent delay of sleep timing and the circadian rhythm.

\section{Supplementary Information}

The online version contains supplementary material available at https://doi. org/10.1186/s40101-021-00257-x.

Additional file 1: Figure S1. The pictures used in the questionnaire in this study are not allowed to be shown due to copyright issues, but almost the same pictures are shown as additional files.

Additional file 2: Table S1. Demographic data and sleep habits in Japanese and Chinese students whose illuminance was measured. 


\section{Acknowledgements}

We would like to thank Ms. Kaoru Inami for supporting our experiment.

\section{Authors' contributions}

$\mathrm{SH}, \mathrm{YL}, \mathrm{SK}$, and $\mathrm{AY}$ contributed to the design of the experiment. SH, YL, JQ and $Y Z$ performed the experiments. $S H, J Q, Y Z, M O$, and $S L$ analyzed the data. SH wrote the manuscript with advice from YL. SK and AY participated in the discussion and preparation of the manuscript. All authors read and approved the final manuscript.

\section{Funding}

This work was supported by JSPS KAKENHI Grant Number 17 K18926.

\section{Availability of data and materials}

The datasets analyzed in this study are not publicly available due to a privacy policy but are available from the corresponding author on reasonable request.

\section{Declarations}

\section{Ethics approval and consent to participate}

The study was approved by the Ethics Committee of Kyushu University (Approval No. 157). Written informed consent was obtained from all participants.

\section{Consent for publication}

Not applicable

\section{Competing interests}

The authors declare that they have no competing interests.

\begin{abstract}
Author details
'Department of Human Science, Faculty of Design, Kyushu University, 4-9-1

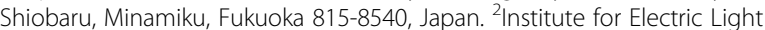
Sources, Fudan University, Shanghai 200433, China. ${ }^{3}$ Department of Kansei Science, Graduate School of Integrated Frontier Sciences, Kyushu University, 4-9-1 Shiobaru, Minamiku, Fukuoka 815-8540, Japan. ${ }^{4}$ Laboratory of Environmental Ergonomics, Faculty of Engineering, Hokkaido University, Kita 8, Nishi 5, Kita-ku, Sapporo, Hokkaido 060-0808, Japan. ${ }^{5}$ Department of Sleep-Wake Disorders, National Institute of Mental Health, National Center of Neurology and Psychiatry, 4-1-1, Ogawa-Higashi, Kodaira, Tokyo 187-8553, Japan
\end{abstract}

Received: 29 December 2020 Accepted: 31 May 2021

Published online: 08 June 2021

\section{References}

1. Khalsa SB, Jewett ME, Cajochen C, Czeisler CA. A phase response curve to single bright light pulses in human subjects. J Physiol. 2003;549(Pt 3):94552. https://doi.org/10.1113/jphysiol.2003.040477.

2. St Hilaire MA, Gooley JJ, Khalsa SB, Kronauer RE, Czeisler CA, Lockley SW. Human phase response curve to a $1 \mathrm{~h}$ pulse of bright white light. J Physiol. 2012;590(Pt 13):3035-45. https://doi.org/10.1113/jphysiol.2012.227892.

3. Lewy AJ, Nurnberger JI Jr, Wehr TA, Pack D, Becker LE, Powell RL, et al. Supersensitivity to light: possible trait marker for manic-depressive illness. Am J Psychiatry. 1985;142(6):725-7. https://doi.org/10.1176/ajp.142.6.725.

4. Cajochen C. Alerting effects of light. Sleep Med Rev. 2007:11(6):453-64. https://doi.org/10.1016/j.smrv.2007.07.009.

5. Lockley SW, Gooley J. Circadian photoreception: spotlight on the brain. Curr Biol. 2006;16(18):R795-7. https://doi.org/10.1016/j.cub.2006.08.039.

6. Daneault V, Dumont M, Masse E, Vandewalle G, Carrier J. Light-sensitive brain pathways and aging. J Physiol Anthropol. 2016;35(1):9. https://doi. org/10.1186/s40101-016-0091-9.

7. Katsuura T, Lee S. A review of the studies on nonvisual lighting effects in the field of physiological anthropology. J Physiol Anthropol. 2019;38(1):2. https://doi.org/10.1186/s40101-018-0190-x.

8. Lucas RJ, Peirson SN, Berson DM, Brown TM, Cooper HM, Czeisler CA, et al. Measuring and using light in the melanopsin age. Trends Neurosci 2014; 37(1):1-9. https://doi.org/10.1016/j.tins.2013.10.004.
9. Burgess HJ, Molina TA. Home lighting before usual bedtime impacts circadian timing: a field study. Photochem Photobiol. 2014;90(3):723-6. https://doi.org/10.1111/php.12241.

10. Gooley JJ, Chamberlain K, Smith KA, Khalsa SB, Rajaratnam SM, Van Reen E, et al. Exposure to room light before bedtime suppresses melatonin onset and shortens melatonin duration in humans. J Clin Endocrinol Metab. 2011; 96(3):E463-72. https://doi.org/10.1210/jc.2010-2098.

11. Brainard GC, Hanifin JP, Greeson JM, Byrne B, Glickman G, Gerner E, et al. Action spectrum for melatonin regulation in humans: evidence for a novel circadian photoreceptor. J Neurosci. 2001;21(16):6405-12. https://doi.org/1 0.1523/JNEUROSCI.21-16-06405.2001.

12. Lockley SW, Brainard GC, Czeisler CA. High sensitivity of the human circadian melatonin rhythm to resetting by short wavelength light. J Clin Endocrinol Metab. 2003;88(9):4502-5. https://doi.org/10.1210/jc.2003-030570.

13. Thapan K, Arendt J, Skene DJ. An action spectrum for melatonin suppression: evidence for a novel non-rod, non-cone photoreceptor system in humans. J Physiol. 2001;535(Pt 1):261-7. https://doi.org/10.1111/j.14697793.2001.t01-1-00261.x.

14. Berson DM, Dunn FA, Takao M. Phototransduction by retinal ganglion cells that set the circadian clock. Science. 2002;295(5557):1070-3. https://doi. org/10.1126/science.1067262.

15. Provencio I, Rodriguez IR, Jiang G, Hayes WP, Moreira EF, Rollag MD. A nove human opsin in the inner retina. J Neurosci. 2000;20(2):600-5. https://doi. org/10.1523/JNEUROSCI.20-02-00600.2000.

16. Chellappa SL, Steiner R, Blattner P, Oelhafen P, Gotz T, Cajochen C. Nonvisual effects of light on melatonin, alertness and cognitive performance: can blue-enriched light keep us alert? PLoS One. 2011;6(1):e16429. https:// doi.org/10.1371/journal.pone.0016429.

17. Kraneburg A, Franke S, Methling R, Griefahn B. Effect of color temperature on melatonin production for illumination of working environments. Applied Ergonomics. 2017;58:446-53. https://doi.org/10.1016/j.apergo.2016.08.006.

18. Kozaki T, Koga S, Toda N, Noguchi H, Yasukouchi A. Effects of short wavelength control in polychromatic light sources on nocturnal melatonin secretion. Neurosci Lett. 2008;439(3):256-9. https://doi.org/10.1016/..neulet.2 008.05.035.

19. Deguchi T, Sato M. The effect of color temperature of lighting sources on mental activity level. Ann Physiol Anthropol. 1992;11(1):37-43. https://doi. org/10.2114/ahs1983.11.37.

20. Kobayashi H, Sato M. Physiological responses to illuminance and color temperature of lighting. Ann Physiol Anthropol. 1992;11(1):45-9. https://doi. org/10.2114/ahs1983.11.45

21. Morita T, Tokura H. Effects of lights of different color temperature on the nocturnal changes in core temperature and melatonin in humans. Appl Human Sci. 1996;15(5):243-6. https://doi.org/10.2114/jpa.15.243.

22. Yasukouchi A, Ishibashi K. Non-visual effects of the color temperature of fluorescent lamps on physiological aspects in humans. J Physiol Anthropol Appl Human Sci. 2005;24(1):41-3. https://doi.org/10.2114/jpa.24.41.

23. Brainard GC, Hanifin JP, Warfield B, Stone MK, James ME, Ayers M, et al. Short-wavelength enrichment of polychromatic light enhances human melatonin suppression potency. J Pineal Res. 2015;58(3):352-61. https://doi. org/10.1111/jpi.12221.

24. Lasauskaite R, Cajochen C. Influence of lighting color temperature on effortrelated cardiac response. Biol Psychol. 2018;132:64-70. https://doi.org/10.101 6/j.biopsycho.2017.11.005.

25. Lee Sl, Matsumori K, Nishimura K, Nishimura Y, Ikeda Y, Eto T, et al. Melatonin suppression and sleepiness in children exposed to blue-enriched white LED lighting at night. Physiol Rep. 2018;6(24):e13942. https://doi.org/1 $0.14814 /$ phy2.13942

26. Higuchi S, Lee SI, Kozaki T, Harada T, Tanaka I. Late circadian phase in adults and children is correlated with use of high color temperature light at home at night. Chronobiol Int. 2016;33(4):448-52. https://doi.org/10.3109/0742052 8.2016.1152978.

27. Roenneberg T, Kuehnle T, Juda M, Kantermann T, Allebrandt K, Gordijn M, et al. Epidemiology of the human circadian clock. Sleep Med Rev. 2007: 11(6):429-38. https://doi.org/10.1016/j.smrv.2007.07.005.

28. Ohida T, Kamal AM, Uchiyama M, Kim K, Takemura S, Sone T, et al. The influence of lifestyle and health status factors on sleep loss among the Japanese general population. Sleep. 2001;24(3):333-8. https://doi.org/10.1 093/sleep/24.3.333.

29. Roenneberg T, Allebrandt KV, Merrow M, Vetter C. Social jetlag and obesity. Curr Biol. 2012;22(10):939-43. https://doi.org/10.1016/j.cub.2012.03.038. 
30. Kitamura S, Hida A, Aritake S, Higuchi S, Enomoto M, Kato M, et al. Validity of the Japanese version of the Munich ChronoType Questionnaire. Chronobiol Int. 2014;31(7):845-50. https://doi.org/10.3109/07420528.2014. 914035.

31. Wittmann M, Dinich J, Merrow M, Roenneberg T. Social jetlag: misalignment of biological and social time. Chronobiol Int. 2006;23(1-2):497-509. https:// doi.org/10.1080/07420520500545979.

32. Komada Y, Okajima I, Kitamura S, Inoue Y. A survey on social jetlag in Japan: a nationwide, cross-sectional internet survey. Sleep and Biological Rhythms. 2019;17(4):417-22. https://doi.org/10.1007/s41105-019-00229-w.

33. Levandovski R, Dantas G, Fernandes LC, Caumo W, Torres I, Roenneberg T, et al. Depression scores associate with chronotype and social jetlag in a rural population. Chronobiol Int. 2011;28(9):771-8. https://doi.org/10.3109/ 07420528.2011.602445.

34. Haraszti RA, Ella K, Gyongyosi N, Roenneberg T, Kaldi K. Social jetlag negatively correlates with academic performance in undergraduates. Chronobiol Int. 2014;31(5):603-12. https://doi.org/10.3109/07420528.2013. 879164.

35. Komada Y, Ikeda Y, Sato M, Kami A, Masuda C, Shibata S. Social jetlag and menstrual symptoms among female university students. Chronobiol Int. 2019;36(2):258-64. https://doi.org/10.1080/07420528.2018.1533561.

36. Burgess $\mathrm{HJ}$, Eastman $\mathrm{Cl}$. Early versus late bedtimes phase shift the human dim light melatonin rhythm despite a fixed morning lights on time. Neurosci Lett. 2004;356(2):115-8. https://doi.org/10.1016/..neulet.2003.11.032.

37. Higuchi S, Motohashi Y, Maeda T, Ishibashi K. Relationship between individual difference in melatonin suppression by light and habitual bedtime. J Physiol Anthropol Appl Human Sci. 2005;24(4):419-23. https:// doi.org/10.2114/jpa.24.419.

38. van der Meijden WP, Van Someren JL, Te Lindert BH, Bruijel J, van Oosterhout F, Coppens JE, et al. Individual differences in sleep timing relate to melanopsin-based phototransduction in healthy adolescents and young adults. Sleep. 2016;39(6):1305-10. https://doi.org/10.5665/sleep.5858.

39. Phillips AJK, Vidafar P, Burns AC, McGlashan EM, Anderson C, Rajaratnam SMW, et al. High sensitivity and interindividual variability in the response of the human circadian system to evening light. Proc Natl Acad Sci U S A. 2019;116(24):12019-24.

40. Lee Sl, Hida A, Kitamura S, Mishima K, Higuchi S. Association between the melanopsin gene polymorphism OPN4*lle394Thr and sleep/wake timing in Japanese university students. J Physiol Anthropol. 2014;33(1):9. https://doi. org/10.1186/1880-6805-33-9.

41. Higuchi S, Hida A, Tsujimura S, Mishima K, Yasukouchi A, Lee SI, et al. Melanopsin gene polymorphism I394T Is associated with pupillary light responses in a dose-dependent manner. PLoS One. 2013;8(3):e60310. https://doi.org/10.1371/journal.pone.0060310.

\section{Publisher's Note}

Springer Nature remains neutral with regard to jurisdictional claims in published maps and institutional affiliations.

Ready to submit your research? Choose BMC and benefit from:

- fast, convenient online submission

- thorough peer review by experienced researchers in your field

- rapid publication on acceptance

- support for research data, including large and complex data types

- gold Open Access which fosters wider collaboration and increased citations

- maximum visibility for your research: over $100 \mathrm{M}$ website views per year

At BMC, research is always in progress.

Learn more biomedcentral.com/submissions 